\title{
PENGALAMAN KERJA DAN PENILAIAN PROFESIONAL AUDITOR: BUKTI DARI MAHASISWA DI YOGYAKARTA
}

\author{
Rizki Hamdani, Satrio Pamungkas, Kumalahadi \\ Fakultas Bisnis dan Ekonomika, Universitas Islam Indonesia, Yogyakarta, Indonesia \\ Email: rizki.hamdani@uii.ac.id, satriopamungkas058@gmail.com
}

\author{
A R T I C L E I N F O \\ Article History: \\ Received: 26 July 2020 \\ Accepted: 29 October 2020 \\ Available online: 30 October 2020 \\ Keywords: \\ Pengalaman Auditor, \\ Profesional Auditor, \\ Fraud Risk, Pengendalian Internal, \\ Budaya.
}

\begin{abstract}
A B S T R A C T
Penelitian ini bertujuan untuk mendeteksi pengaruh pengalaman kerja auditor terhadap penilaian profesional auditor. Sebanyak 100 orang responden dari mahasiswa $S 1$ akuntansi dilibatkan dalam penelitian ini. Penelitian ini menggunakan desain eksperimen untuk menguji pengaruh pengalaman kerja auditor terhadap professional judgment auditor yang secara khusus dilihat dari evaluasi lingkungan pengendalian internal untuk perusahaan yang beroperasi di berbagai negara dengan budaya yang berbeda karakteristik dan penilaian fraud risk untuk perusahaan yang beroperasi di berbagai negara dengan budaya yang berbeda karakteristik. Hasil penelitian menunjukkan bahwa lamanya pengalaman kerja auditor berpengaruh terhadap penilaian fraud risk dilihat dari budaya individualisme dan kolektivisme, namun tidak berpengaruh terhadap evaluasi pengendalian internal. Lamanya pengalaman kerja auditor juga tidak berpengaruh terhadap penilaian fraud risk dilihat dari budaya high uncertainty avoidance vs low uncertainty avoidance. Penelitian ini memberikan wawasan kepada kantor akuntan publik, perusahan, dan pemerintah untuk mengetahui bagaimana dalam melihat dan melakukan penilaian terhadap profesional auditor.
\end{abstract}

\section{Pendahuluan}

Pengauditan (auditing) adalah suatu pemeriksaan yang dilakukan secara kritis dan sistematis oleh pihak yang independen, terhadap laporan keuangan yang telah disusun oleh manajemen beserta catatan-catatan pembukuan dan bukti-bukti pendukungnya, dengan tujuan untuk dapat memberikan pendapat mengenai kewajaran laporan keuangan (Agus, 2004). Laporan keuangan yang telah diaudit dapat di publikasikan hasilnya dan digunakan oleh pihak-pihak yang berkepentingan atas laporan keuangan tersebut.

Kualitas dari judgment menjadi tolak ukur kinerja seorang auditor apakah telah menjalankan tugasnya dengan baik sesuai dengan ketentuan yang ada (Putri dan Laksito, 2013). Menurut Komalasari dan Hernawati (2015) kualitas kinerja auditor dapat diukur dan ditinjau dari kualitas judgment yang dihasilkan dan keputusan yang diambil oleh seorang auditor. Semakin bagus keputusan dan pertimbangan yang dihasilkan maka akan menghasilkan kualitas audit yang bagus.

Hasil judgment tersebut dilihat dari bukti yang didapatkan kemudian seperti apa pengembangan bukti tersebut sehingga memberikan kepercayaan yang lahir dari kemampuan auditor dalam menginterpretasikan bukti-bukti (Rahayu, 2016). Pendapat lain menyatakan bahwa audit judgment adalah suatu kebijakan yang dikeluarkan oleh auditor dalam 
memberikan pendapat terkait hasil audit yang merujuk pada penyusunan suatu ide, opini atau estimasi-estimasi terhadap suatu objek dan kejadian suatu peristiwa (Komalasari dan Hernawati, 2015).

Terdapat banyak faktor-faktor yang mendukung seorang auditor dalam memberikan hasil judgment yang baik, akurat dan berkualitas. Salah satu faktor-faktor yang mendukung seorang auditor dalam memberikan hasil judgment yang baik di antaranya adalah pengalaman audit (Haynes et. al, 1998). Semakin banyak pengalaman yang dimiliki seseorang akan berpengaruh terhadap pekerjaan yang dilakukan dan memberikan potensi yang besar bagi seseorang untuk melakukan pekerjaan yang lebih baik (Rahayu, 2016).

Penilaian resiko penipuan juga menjadi salah satu langkah penting dalam pemeriksaan audit atas laporan keuangan pada entitas bisnis. Auditor independen yang mempunyai pengalaman atau yang tidak mempunyai pengalaman harus membuat keputusan berdasarkan pada penilaian profesional mereka sekalipun entitas (klien audit) auditor tersebut berada di kota atau daerah yang berbeda. Profesionalisme sangat penting dalam melakukan audit agar dalam proses audit tidak melakukan kecurangan yang berimplikasi pada kualitas audit yang buruk (Hamdani et al., 2020). Salah satu faktor yang berpengaruh terhadap proses pengambilan keputusan ialah kota atau daerah tempat auditor melakukan prosedur kerja lapangan, khususnya ketika klien berada di suatu kota atau daerah dengan karakteristik budaya yang berbeda (Cohen et. al., 1993).

\section{Tinjauan Pustaka dan Pengembangan Hipotesis}

2.1 Teori Kognitif

Menurut Praditaningrum dan Januarti (2012), dalam teori kognitif, auditor akan mengintegrasikan pengalaman serta pengetahuan yang dimilikinya dalam melaksanakan tugas yang akan datang. Teori kognitif berhubungan dengan keahlian dan pengalaman seorang auditor dalam mengambil suatu pertimbangan, pendapat atau keputusan didasarkan atas pengalaman dan keahliannya terkait dengan pelaksanaan pemeriksaan (Alamri et. al., 2017). Perkembangan kognitif menjelaskan bahwasanya pola pikir orang yang minim akan pengalaman tidak hanya kurang matang dan tidak terstruktur dibandingkan dengan orang yang penuh akan pengalaman tetapi juga berbeda secara kualitatif (Ibda, 2015).

Teori kognitif pada penelitian ini dapat digunakan sebagai bentuk penjelasan seorang auditor melakukan pertimbangan berdasarkan kemampuan dan pengalamannya dalam melaksanakan tugas audit. Semakin auditor mempunyai banyak pengalaman maka akan memberikan pengaruh positif pada judgment yang dibuat akan lebih berkualitas karena saat auditor melakukan tugas auditnya maka auditor akan belajar dari pengalaman sebelumnya.

\subsection{Audit Judgment}

Dalam proses audit judgment mempunyai tahapan-tahapan yang perlu dilakukan untuk mendapatkan hasil judgment yang berkualitas yaitu merumuskan persoalan, mengumpulkan informasi yang relevan, mencari alternatif tindakan, menganalisis alternatif yang fleksibel, memilih alternatif yang terbaik, kemudian pelaksanaan dan mengevaluasi terhadap hasil akhirnya (Komalasari dan Hernawati, 2015; Sanger et. al., 2016).

\subsection{Pengalaman Audit dan Evaluasi \\ Lingkungan}

Auditor yang mempunyai pengalaman akan memiliki kelebihan dalam mencari bukti, mendeteksi kesalahan, kemudian memahami dan mencari penyebab dari kesalahan secara menyeluruh dan akurat (Novarianto, 2010). Menurut (Basri, 2011), auditor yang berpengalaman akan lebih peka terhadap kesalahan yang terjadi oleh karena itu akan terhindar dari salah paham terhadap kekeliruan tersebut.

Lebih lanjut Ashton dan Brown (1980) menyebutkan auditor yang berpengalaman akan lebih banyak melakukan persetujuan dibandingkan dengan auditor yang minim akan pengalaman. Di sisi lain, auditor yang berpengalaman akan lebih paham dalam menjelaskan keputusan yang ia ambil dibandingkan dengan auditor yang kurang akan pengalaman. Selain itu juga auditor berpengalaman akan lebih konsisten dan tanggung jawab terhadap tanggapan mereka pada informasi dan penilaian resiko 
pengendalian dibandingkan dengan auditor yang kurang berpengalaman.

Cohen dan Kida (1989) menyatakan bahwa prosedur audit substansial atau yang biasa disebut "review analitis" memiliki dampak yang lebih signifikan dari penilaian audit manager dibandingkan dengan penilaian dari audior senior. Menurut Ríos-Figueroa dan Cardona (2013) auditor yang mempunyai jenjang jabatan lebih tinggi (lebih berpengalaman) akan menunjukkan sikap lebih selektif terhadap informasi yang relevan dibandingkan dengan auditor yang mempunyai jenjang jabatan lebih rendah (kurang berpengalaman). Selain itu juga auditor berpengalaman akan lebih konsisten dan tanggung jawab terhadap tanggapan mereka pada informasi dan penilaian resiko pengendalian dibandingkan dengan auditor yang kurang berpengalaman (Ríos-Figueroa \& Cardona, 2013).

H1:Lamanya pengalaman kerja auditor berpengaruh terhadap evaluasi lingkungan pengendalian internal untuk perusahaan dengan budaya yang berbeda karakteristik.

\subsection{Pengalaman Audit dan Fraud}

Fraud laporan keuangan merupakan penyalahgunaan kewenangan yang dilakukan terhadap pelaporan keuangan yang biasanya dilakukan oleh manajemen (Sunaryo et. al., 2019). Tingkatan fraud dapat diukur dengan seberapa besar keseriusan terjadinya fraud yang dapat merugikan organisasi (Busra et. al., 2019). Pada suatu kondisi dimana perusahaan yang teridentifikasi melakukan suatu fraud, maka seorang auditor harus lebih teliti dan skeptisme dalam mengevaluasi apakah kecurangan tersebut berdampak signifikan pada laporan keuangan suatu entitas (Brulenski dan Zayas, 2004). Sehingga, kualitas dan keterampilan auditor sebagai pemeriksa fraud dapat ditingkatkan untuk memudahkan dalam mengungkap kecurangan yang terjadi (Sumartono et. al., 2020).

Novarianto (2010) menyatakan bahwa pengalaman dapat diukur secara lebih spesifik dari jam terbang seseorang bekerja atau menjalankan tugasnya. Selain itu pekerjaan atau tugas yang dilakukan secara berulang dan berkelanjutan akan memberikan efek bagi seseorang untuk belajar dari kesalahan sebelumnya agar lebih baik lagi kedepannya. Auditor harus mempertimbangkan aspek budaya ketika melakukan perencanaan audit karena pengalaman dan pengetahuan yang dimiliki oleh auditor berpengaruh terhadap proses pengambilan keputusan dalam suatu audit (Hughes et al., 2009; Ríos-Figueroa dan Cardona, 2013). Hasil yang diperoleh dalam penelitian yang dilakukan oleh Sim (2010) juga menjelaskan secara tersirat bahwa laporan auditor tentang pengendalian internal bahwa budaya nasional merupakan faktor dalam pertimbangan seorang auditor dalam penilaian mereka tentang resiko pengendalian.

Menurut penelitian yang dilakukan oleh Ashton dan Brown (1980) juga menjelaskan bahwa penilaian yang dibuat auditor independen yang berpengalaman akan lebih relatif terhadap sistem pengendalian internal. Libby dan Frederick (1990) menemukan bahwa auditor yang berpengalaman akan lebih menunjukan pehamanan nya tentang kesalahan pada laporan keuangan dan lebih mampu menghasilkan hipotesis yang menjelaskan kesalahan dalam laporan keuangan dan juga memberikan penilaian lebih cepat dan tepat daripada rekan-rekan mereka yang kurang berpengalaman. Menurut Ríos-Figueroa dan Cardona (2013), pengalaman merupakan salah satu indikator penting bagi seorang auditor yang mempengaruhi penilaiannya pada sebuah faktor resiko terjadinya fraud. Davis dan Ruhe (2003) menyimpulkan bahwa auditor yang lebih berpengalaman akan menunjukan sikap yang lebih selektif terhadap informasi. Menurut Watson (2003) orang-orang dengan latar belakang budaya yang berbeda memiliki pendapat berbeda bagaimana menangani fraud.

Peneliti sebelumnya telah banyak mengidentifikasi beberapa faktor yang terkait dengan budaya yang memungkinkan terjadinya suatu fraud. Davis dan Ruhe (2003) menemukan bahwa dimensi kolektivisme dan jarak kekuasaan tampaknya terkait dengan korupsi. Menurut Husted (1999) profil budaya seorang koruptor negara dikaitkan dengan tingkat kekuatan yang tinggi dan penghindaran ketidakpastian yang tinggi.

Getz dan Volkema (2001) menyatakan bahwa suatu negara dengan penolakan yang tinggi terhadap penghindaran ketidakpastian dan negara dengan jarak kekuasaan yang besar 
tampaknya terkait secara positif dengan korupsi.

Menurut Mohd-Sanusi et. al., (2015) penilaian resiko fraud merupakan suatu proses yang sistematis digunakan untuk mengidentifikasi dan mengevaluasi sebuah kejadian atau kondisi tertentu, misalnya terdapat kemungkinan terjadinya resiko fraud pada perusahaan. Suraida (2005) mengungkapkan bahwa seorang auditor akan belajar dari kesalahan-kesalahan yang ditemuinya pada proses audit yang pernah dilakukan, sehingga auditor yang berpengalaman lebih bijak dalam mengidentifikasi fraud. Penelitian ini menggunakan empat dimensi budaya yang telah digunakan oleh Hofstede (2001) yaitu individualisme dan kolektivisme, jarak kekuasaan, ketidakpastian penghindaran dan visi jangka pendek dan panjang. Keempat dimensi budaya tersebut digunakan untuk menguji pengaruh perbedaan budaya dan menilai apakah pengalaman memiliki dampak terhadap keputusan yang dibuat oleh auditor terkait penilaian mereka tentang fraud risk pada klien.

H2: Lamanya pengalaman kerja auditor berpengaruh terhadap penilaian risiko fraud untuk perusahaan dengan budaya yang berbeda karakteristik.

\section{Metode Penelitian}

Penelitian ini menggunakan pendekatan eksperimen untuk menguji pengaruh pengalaman kerja terhadap penilaian profesional (professional judgment) auditor, lebih spesifiknya yaitu terhadap evaluasi lingkungan pengendalian internal untuk perusahaan yang beroperasi di berbagai negara dengan budaya yang berbeda karakteristik dan penilaian fraud risk untuk perusahaan yang beroperasi di berbagai negara dengan budaya yang berbeda karakteristik. Variabel independen yang diteliti dalam penelitian ini adalah pengalaman kerja auditor. Variabel dependen yaitu evaluasi lingkungan pengendalian internal dan penilaian kemungkinan terjadi resiko fraud pada perusahaan yang mempunyai karakteristik budaya yang berbeda. Kuisioner dibagikan kepada Mahasiswa Program Studi Akuntansi Universitas Islam Indonesia Yogyakarta yang telah mengambil dan lulus pada mata kuliah pengauditan 1 dan pengauditan 2 karena mahasiswa tersebut sudah belajar dan diharapkan telah paham mengenai evaluasi pengendalian internal dan fraud risk.

Sampel yang digunakan adalah 100 koresponden yang akan diberikan beberapa treatment yang berbeda. Penentuan sampel penelitian ini menggunakan metode random sampling. Pada penelitian ini subjek atau responden ditempatkan dalam kelompok manipulasi secara acak hal ini berkaitan dengan sampel yang dipilih diharapkan dapat merepresentasikan populasi secara keseluruhan melalui hasil yang akan didapatkan dari penelitian yang ada.

Peneliti menggunakan laboratory experiment pada penelitian ini dan mempunyai hak dalam menentukan keadaan serta kasus yang akan diberikan kepada para koresponden penelitian Nahartyo (2012), kemudian menggunakan teknik kuesioner untuk mendapatkan data-data yang dibutuhkan dalam objek penelitian dengan memberikan pertanyaan-pertanyaan yang telah disusun secara tertulis dan sistematis serta yang telah dipersiapkan terlebih dahulu sebelum diberikan kepada koresponden. Selanjutnya, kuisioner tersebut diberikan kepada koresponden untuk dijawab dan terakhir diserahkan kembali kepada peneliti.

Pada penelitian ini, semua responden auditor diklasifikasikan berdasarkan 2 bagian yaitu bagian pertama auditor mempunyai sedikit pengalaman dengan klasifikasi lama bekerja 0-2 tahun, bagian kedua auditor mempunyai banyak pengalaman dengan klasifikasi lama bekerja 10 tahun. Setelah itu responden memberikan penilaian mereka dengan peringkat jawaban ada di 5 skala likert, mulai dari 1 (sangat rendah) hingga 5 (sangat tinggi).

Matriks eksperimen pada tabel 1 menjelaskan mengenai hipotesis dari penelitian, kemudian melakukan metode eksperimen ini dengan membagi menjadi 12 Sell.

SELL 1: Auditor banyak pengalaman dan evaluasi lingkungan pengendalian internal dilihat dari budaya individualisme vs kolektivisme 
SELL 2: Auditor sedikit pengalaman dan evaluasi lingkungan pengendalian internal dilihat dari budaya individualisme vs kolektivisme

SELL 3: Auditor banyak pengalaman dan evaluasi pengendalian internal dilihat dari budaya high power distance vs low power distance

SELL 4: Auditor sedikit pengalaman dan evaluasi pengendalian internal dilihat dari budaya high power distance vs low power distance

SELL 5: Auditor banyak pengalaman dan evaluasi pengendalian internal dilihat dari budaya high uncertainty avoidance vs low uncertainty avoidance

SELL 6: Auditor sedikit pengalaman dan evaluasi pengendalian internal dilihat dari budaya high uncertainty avoidance vs low uncertainty avoidance

SELL 7: Auditor banyak pengalaman dan penilaian fraud risk dilihat dari budaya individualisme vs kolektivisme

SELL 8: Auditor sedikit pengalaman dan penilaian fraud risk dilihat dari budaya individualisme vs kolektivisme

SELL 10: Auditor sedikit pengalaman dan penilaian fraud risk dilihat dari budaya high power distance vs low power distance

SELL 11: Auditor banyak pengalaman dan penilaian fraud risk dilihat dari budaya high uncertainty avoidance vs low uncertainty avoidance

SELL 12: Auditor sedikit pengalaman dan penilaian fraud risk dilihat dari budaya high uncertainty avoidance vs low uncertainty avoidance

Tabel 1. Matriks Eksperimen

\begin{tabular}{clcc}
\hline Variabel & \multicolumn{1}{c}{ Karakteristik Budaya } & $\begin{array}{c}\text { Auditor Banyak } \\
\text { Pengalaman }\end{array}$ & $\begin{array}{c}\text { Auditor Sedikit } \\
\text { Pengalaman }\end{array}$ \\
\hline \multirow{2}{*}{$\begin{array}{c}\text { Evaluasi Lingkungan } \\
\text { Pengendalian Internal }\end{array}$} & Individualisme vs Kolektivisme & SELL 1 & SELL 2 \\
& High Power Distance vs Low Power Distance & SELL 3 & SELL 4 \\
& High Uncertainty Avoidance vs Low Uncertainty Avoidance & SELL 5 & SELL 6 \\
\hline \multirow{2}{*}{ Penilaian Fraud Risk } & Individualisme vs Kolektivisme & SELL 7 & SELL 8 \\
& High Power Distance vs Low Power Distance & SELL 9 & SELL 10 \\
& High Uncertainty Avoidance vs Low Uncertainty Avoidance & SELL 11 & SELL 12 \\
\hline
\end{tabular}

\section{Hasil Penelitian dan Pembahasan}

Teknik pengumpulan data dalam penelitian ini dengan menggunakan kuisioner. Data yang terkumpul sebanyak 100 kuesioner dan telah memenuhi syarat untuk digunakan pada penelitian ini.
Pada tabel 2 berisi tentang informasi yang berkaitan dengan demografi responden berdasarkan jenis kelamin, angkatan kuliah, data usia, dan telah lulus pada mata kuliah pengauditan 1 dan 2 .

Tabel 2. Karakteristik Demografi Responden

\begin{tabular}{|c|c|c|c|}
\hline \multicolumn{2}{|c|}{ Demografi Responden } & Jumlah Responden & Presentase \\
\hline \multirow{2}{*}{ Jenis Kelamin } & Laki-laki & 42 & $42 \%$ \\
\hline & Perempuan & 58 & $58 \%$ \\
\hline \multirow{3}{*}{ Angkatan Kuliah } & 2014 & 4 & $4 \%$ \\
\hline & 2015 & 33 & $33 \%$ \\
\hline & 2016 & 63 & $63 \%$ \\
\hline \multirow{6}{*}{ Usia } & 19 & 18 & $18 \%$ \\
\hline & 20 & 25 & $25 \%$ \\
\hline & 21 & 33 & $33 \%$ \\
\hline & 22 & 20 & $20 \%$ \\
\hline & 23 & 3 & $3 \%$ \\
\hline & $>23$ & 1 & $1 \%$ \\
\hline \multirow{2}{*}{ Mata Kuliah } & Lulus pengauditan 1 dan 2 & 100 & $100 \%$ \\
\hline & Tidak lulus pengauditan 1 dan 2 & 0 & $0 \%$ \\
\hline
\end{tabular}

Sumber: Data Olahan (2020) 


\subsection{Uji Validitas dan Reliabilitas}

Tabel 3 menunjukkan bahwa 8 butir pertanyaan untuk evaluasi pengendalian internal dan penilaian fraud risk pada karakteristik budaya individualisme dan kolektivisme terbukti valid atau mampu mengukur sesuatu yang benar-benar diukur dalam penelitian. Hal itu dapat diketahui dari hasil uji validitas yang menunjukkan kevalidan dengan dasar pengambilan keputusan yaitu Rhitung > R-tabel.

Tabel 3. Hasil Uji Validitas

\begin{tabular}{|c|c|c|c|}
\hline \multicolumn{4}{|c|}{$\begin{array}{c}\mathrm{N}=50 \\
\text { alpha= } 0,05 \\
\text { Sig (2-tailed)=0,000 }\end{array}$} \\
\hline No. Soal & R-hitung & R-tabel & Keterangan \\
\hline 1 & 0,489 & 0,278 & Valid \\
\hline 2 & 0,715 & 0,278 & Valid \\
\hline 3 & 0,665 & 0,278 & Valid \\
\hline 4 & 0,650 & 0,278 & Valid \\
\hline 5 & 0,753 & 0,278 & Valid \\
\hline 6 & 0,772 & 0,278 & Valid \\
\hline 7 & 0,754 & 0,278 & Valid \\
\hline 8 & 0,683 & 0,278 & Valid \\
\hline
\end{tabular}

Tabel 4 menunjukan hasil uji reliabilitas yang dilakukan bahwa seluruh butir pertanyaan dari variabel evaluasi pengendalian internal dan penilaian fraud risk pada karakteristik budaya yang berbeda dinyatakan reliabel yang mana responden bersikap relatif konsisten terhadap segala manipulasi yang diberikan.

Tabel 4. Hasil Uji Reliabilitas

\begin{tabular}{lccc}
\hline \multicolumn{1}{c}{ Variabel } & $\begin{array}{c}\text { Croanbach' } \\
\text { Alpha }\end{array}$ & $\begin{array}{c}\text { Nof } \\
\text { items }\end{array}$ & Keterangan \\
\hline $\begin{array}{l}\text { Evaluasi Pengendalian } \\
\text { internal (individualisme } \\
\text { vs kolektivisme) }\end{array}$ & 0,497 & 4 & Reliabel \\
$\begin{array}{l}\text { Penilaian Fraud Risk } \\
\text { (individualisme vs } \\
\text { kolektivisme) } \\
\text { Evaluasi Pengendalian }\end{array}$ & 0,724 & 4 & Reliabel \\
$\begin{array}{l}\text { internal (Power } \\
\text { Distanace) } \\
\text { Penilaian Fraud Risk } \\
\text { (Power Distanace) }\end{array}$ & 0,705 & 4 & Reliabel \\
$\begin{array}{l}\text { Evaluasi Pengendalian } \\
\text { internal (Uncertainty }\end{array}$ & 0,522 & 4 & Reliabel \\
$\begin{array}{l}\text { Avoidance) } \\
\text { Penilaian Fraud Risk } \\
\text { (Uncertainty }\end{array}$ & 0,832 & 4 & Reliabel \\
Avoidance) & & & \\
\hline
\end{tabular}

\subsection{Uji Normalitas}

Untuk menentukan apakah data berdistribusi normal atau tidak, maka terlebih dahulu dilakukan uji normalitas. Data dikatakan berdistribusi normal jika $p$-value $>\alpha$.
Tabel 5 menunjukkan bahwa data pada seluruh variabel tidak berdistribusi normal, sehingga untuk analisis lebih lanjut dilakukan uji non parametrik dengan menggunakan uji Kruskal Wallis.

Tabel 5. Uji Normalitas

\begin{tabular}{|c|c|c|c|}
\hline Variabel & P-value & $\alpha=5 \%$ & keterangan \\
\hline Evaluasi & & & Tidak \\
\hline $\begin{array}{l}\text { Pengendalian internal } \\
\text { (individualisme vs } \\
\text { kolektivisme) }\end{array}$ & 0,000 & 0,05 & $\begin{array}{l}\text { berdistibusi } \\
\text { normal }\end{array}$ \\
\hline $\begin{array}{l}\text { Penilaian Fraud Risk } \\
\text { (individualisme vs } \\
\text { kolektivisme) }\end{array}$ & 0,004 & 0,05 & $\begin{array}{l}\text { Tidak } \\
\text { berdistibusi } \\
\text { normal }\end{array}$ \\
\hline Evaluasi & & & Tidak \\
\hline $\begin{array}{l}\text { Pengendalian internal } \\
\text { (Power Distanace) }\end{array}$ & 0,001 & 0,05 & $\begin{array}{c}\text { berdistibusi } \\
\text { normal }\end{array}$ \\
\hline $\begin{array}{l}\text { Penilaian Fraud Risk } \\
\text { (Power Distanace) }\end{array}$ & 0,000 & 0,05 & $\begin{array}{l}\text { Tidak } \\
\text { berdistibusi } \\
\text { normal }\end{array}$ \\
\hline $\begin{array}{l}\text { Evaluasi } \\
\text { Pengendalian internal } \\
\text { (Uncertainty } \\
\text { Avoidance) }\end{array}$ & 0,000 & 0,05 & $\begin{array}{l}\text { Tidak } \\
\text { berdistibusi } \\
\text { normal }\end{array}$ \\
\hline $\begin{array}{l}\text { Penilaian Fraud Risk } \\
\text { (Uncertainty } \\
\text { Avoidance) }\end{array}$ & 0,000 & 0,05 & $\begin{array}{c}\text { Tidak } \\
\text { berdistibusi } \\
\text { normal }\end{array}$ \\
\hline
\end{tabular}

\subsection{Pembahasan Hasil Pengujian Hipotesis}

Setelah mengetahui dan melakukan berbagai uji yang telah dipaparkan sebelumnya maka didapatkan hasil pengujian hipotesis (lihat tabel 6).

Tabel 6. Hasil Uji Hipotesis (Kruskal Wallis)

\begin{tabular}{llccc}
\hline Hipotesis & \multicolumn{1}{c}{ Sell } & P-Value & $\alpha=5 \%$ & Hasil \\
\hline \multirow{3}{*}{ H1 } & Sell 1 \& Sell 2 & 0,153 & 0,05 & Ditolak \\
& Sell 3 \& Sell 4 & 0,144 & 0,05 & Ditolak \\
& Sell 5 \& Sell 6 & 0,432 & 0,05 & Ditolak \\
& Sell 7 \& Sell 8 & 0,023 & 0,05 & Gagal \\
H2 & Sell 9 \& Sell 10 & 0,102 & 0,05 & Ditolak \\
& Sell 11\& Sell 12 & 0,520 & 0,05 & Ditolak \\
\hline
\end{tabular}

Pada Tabel 6, menunjukan bahwa P-value $>\alpha(0,05)$ yang artinya tidak terdapat pengaruh yang signifikan variabel pengalaman kerja terhadap evaluasi pengendalian internal. Selain itu juga tidak terdapat pengaruh yang signifikan variabel pengalaman kerja terhadap penilaian fraud risk kecuali pada Sell 7 dan 8 (pengalaman kerja terhadap penilaian fraud risk pada karakteristik budaya individualisme vs kolektivisme).

\section{Pengaruh Pengalaman terhadap Evaluasi Lingkungan}

Dari hasil uji kruskal wallis pada hipotesis pertama diketahui $P$-value masing-masing sebesar 0,153 pada sell 1 dan 2, sebesar 0,144 
pada sell 3 dan 4 dan sebesar 0,432 pada sell 5 dan 6. Keseluruhan nilai $p$-value $>\alpha(0,05)$. Hal ini menunjukkan $\mathrm{H} 1$ ditolak, artinya lamanya pengalaman kerja auditor tidak berpengaruh secara signifikan terhadap evaluasi lingkungan pengendalian internal untuk perusahaan dengan budaya yang berbeda karakteristik.

Hal ini sejalan dengan hasil penelitian sebelumnya yang dilakukan oleh Ríos-Figueroa dan Cardona (2013) yang menunjukkan bahwa tidak ada pengaruh yang signifikan antara pengalaman kerja terhadap penilaian profesional auditor dilihat dari evaluasi pengendalian internal dengan keseluruhan karakteritik budaya yang berbeda (RíosFigueroa dan Cardona, 2013).

Dari hasil yang telah dijabarkan maka dapat ditarik kesimpulan dan implikasi untuk peneliti selanjutnya sebagai referensi yang baru dan untuk KAP dapat mengetahui bahwa auditor yang berpengalaman atau yang tidak berpengalaman tidak mempunyai pengaruh yang signifikan pada penilaian profesional auditor tersebut kecuali pada penilaian fraud risk pada karakterisktik budaya individualisme vs kolektivisme yang mempunyai pengaruh yang signifikan. Hal tersebut mengindikasikan bahwa pengalaman seorang auditor tidak berpengaruh untuk mengevaluasi pengendalian internal perusahaan dengan karakteristik budaya yang berbeda.

\section{Pengaruh Pengalaman Terhadap Risiko Fraud}

Dari hasil pengujian statistik pada hipotesis kedua diketahui $p$-value masing-masing sebesar $0,023<0,05$ pada sell 7 dan 8 , sebesar $0,102>0,05$ pada sell 9 dan 10 dan sebesar $0,520>0,05$ pada sell 11 dan 12. Hal ini menunjukan untuk $\mathrm{H} 2$ dengan lamanya pengalaman kerja auditor terhadap penilaian risiko fraud untuk perusahaan dengan budaya individualisme vs kolektivisme, gagal ditolak. Di sisi lain, lamanya pengalaman kerja auditor terhadap penilaian risiko fraud untuk perusahaan dengan budaya high power distance vs low power distance, ditolak. Selanjutnya, lamanya pengalaman kerja auditor terhadap penilaian risiko fraud untuk perusahaan dengan budaya dengan high uncertainty avoidance vs low uncertainty avoidance, ditolak. Dari hasil uji hipotesis tersebut maka hasil yang didapatkan adalah tidak ada pengaruh yang signifikan pada pengalaman kerja terhadap penilaian profesional auditor dilihat dari penilaian fraud risk pada budaya high power distance vs low power distance, begitu juga jika dilihat dari high uncertainty avoidance vs low uncertainty avoidance. Sedangkan, pengalaman kerja berpengaruh signifikan terhadap penilaian profesional auditor jika dilihat dari penilaian fraud risk pada budaya individualisme vs kolektivisme. Pada peneliti sebelumnya hasil yang didapatkan adalah tidak ada pengaruh yang signifikan pada pengalaman kerja terhadap penilaian profesional auditor dilihat dari evaluasi pengendalian internal dengan keseluruhan karakteritik budaya yang berbeda (Ríos-Figueroa dan Cardona, 2013).

Implikasi terhadap lamanya pengalaman kerja auditor berpengaruh terhadap penilaian risiko fraud untuk perusahaan dengan budaya yang berbeda karakteristik. Hal itu mengindikasikan bahwa auditor yang berpengalaman mempunyai perbedaan penilaian dengan auditor yang tidak berpengalaman dilihat pada penilaian fraud risk dengan budaya individualisme vs kolektivisme.

\section{Kesimpulan}

Berdasarkan dari hasil analisis data yang telah dilakukan pada penelitian ini dapat disimpulkan bahwa jika dilihat dari budaya individualisme vs kolektivisme, lamanya pengalaman kerja auditor tidak berpengaruh terhadap evaluasi pengendalian internal, namun berpengaruh terhadap penilaian fraud risk. Selanjutnya, jika dilihat dari budaya high power distance vs low power distance, lamanya pengalaman kerja auditor tidak berpengaruh terhadap evaluasi pengendalian internal dan juga terhadap penilaian fraud risk. Jika dilihat dari budaya high uncertainty avoidance vs low uncertainty avoidance, lamanya pengalaman kerja auditor tidak berpengaruh terhadap evaluasi pengendalian internal dan juga terhadap penilaian fraud risk.

Implikasi praktis dari penelitian ini untuk Kantor Akuntan Publik (KAP) dapat mengetahui bahwa auditor yang berpengalaman atau yang tidak berpengalaman tidak mempunyai pengaruh yang signifikan pada penilaian profesional auditor tersebut kecuali pada penilaian fraud risk dengan karakterisktik 
budaya individualisme vs kolektivisme yang mempunyai pengaruh yang signifikan.

Pengalaman seorang auditor tidak berpengaruh untuk mengevaluasi pengendalian internal perusahaan dengan karakteristik budaya yang berbeda. Namun, lamanya pengalaman kerja auditor berpengaruh terhadap penilaian risiko fraud untuk perusahaan dengan budaya yang berbeda karakteristik. Hal itu mengindikasikan bahwa auditor yang berpengalaman mempunyai perbedaan penilaian dengan auditor yang tidak berpengalaman dilihat pada penilaian fraud risk dengan budaya individualisme vs kolektivisme.

Adapun keterbatasan dalam penelitian ini hanya melakukan penelitian pada satu variabel independen yaitu pengalaman kerja auditor dan dua variabel independen yaitu evaluasi pengendalian internal dan penilaian fraud risk. Kemudian, responden pada penelitian ini hanya dari mahasiswa di Program Studi Akuntansi Universitas Islam Indonesia. Penelitian selanjutnya dapat dilakukan dengan menambah variabel lain yang dapat mempengaruhi pengalaman kerja auditor dan dapat menambah sampel dengan melaksanakan penelitian tidak hanya di satu universitas tetapi juga dapat dilakukan di beberapa universitas maupun institusi lainnya, kemudian bisa untuk diperbandingkan.

\section{Daftar Pustaka}

Agus, S. (2004). Auditing. Jakarta: Salemba Empat.

Alamri, F., Nangoi, G. B., \& Tinangon, J. J. (2017). Pengaruh Keahlian, Pengalaman, Kompleksitas Tugas dan Independensi Terhadap Audit Judgement Auditor Internal pada Inspektorat Provinsi Gorontalo. Jurnal EMBA, 5(2), 593 - 601.

Ashton, R. H., \& Brown, P. R. (1980). Descriptive modeling of auditors' internal control judgments: Replication and extension. Journal of Accounting Research, 18(1), 269-277.

Basri, H. (2011). P,engaruh Dimensi Professional Auditor Terhadap Pertimbangan Tingkat Materialitas dalam proses. Universitas Hasanuddin.

Brulenski, F. C., \& Zayas, R. J. (2004). Fraud Detection is not by the Numbers. CPA Journal, Summer, 35-37.
Busra, N. F., Ahyaruddin, M., \& Agustiawan, A. (2019). Pengaruh Tingkat Keseriusan Kecurangan, Personal Cost, dan Komitmen Organisasi Terhadap Kecenderungan Melakukan Whistleblowing. Muhammadiyah Riau Accounting and Business Journal, 1(1), 011-019. https://doi.org/10.37859/mrabj.v1i1.1545

Cohen, J. R., Pant, L. W., \& Sharp, D. J. (1993). Culture-based ethical conflicts confronting multinational accounting firms. Accounting Horizons, 7(3), 1-13.

Cohen, J. R., \& Kida, T. (1989). The Impact of Analytical Review Results, Internal Control Reliability, and Experience on Auditors' Use of Analytical Review. Journal of Accounting Research, 27(2), 263-276. https://doi.org/10.2307/2491235

Davis, J. H., \& Ruhe, J. A. (2003). Perceptions of Country Corruption: Antecedents and Outcomes. Journal of Business Ethics, 43(4), 275-288.

Getz, K. A., \& Volkema, R. J. (2001). Culture, Perceived Corruption, and Economics: A Model of Predictors and Outcomes. Business \& Society, 40(1), 7-30. https://doi.org/10.1177/0007650301040001 03

Hamdani, R., Rahimah, I., \& Hafiz, M. S. (2020). Exploring the Professionalism and Dysfunctional Behavior of Public Accountants on Audit Quality. Review of Integrative Business and Economics Research, 9(s3), 9-19.

Haynes, C. M., Jenkins, J. G., \& Nutt, S. R. (1998). The relationship between client advocacy and audit experience: An exploratory analysis. Auditing: A Journal of Practice \& Theory, 17(2), 88-104.

Hofstede, G. (2001). Culture's Consequences: Comparing Values, Behaviors, Institutions, and Organizations Across Nations, (2nd ed). Thousand Oaks, CA: Sage.

Hughes, S. B., Sander, J. F., Higgs, S. D., \& Cullinan, C. P. (2009). The Impact of Cultural Environment on Entry-Level Auditors' Abilities to Perform Analytical Procedures. Journal of International Accounting, Auditing and Taxation, 18(1), 29-43.

Husted, B. W. (1999). Wealth, Culture, and Corruption. Journal of International 
Business Studies, 30(2), 339-359.

Ibda, F. (2015). Perkembangan Kognitif: Teori Jean Piaget. Jurnal Intelektualita, 3(1), 2738.

Komalasari, R., \& Hernawati, E. (2015). Pengaruh Independensi, Kompleksitas Tugas, dan Gender Terhadap Audit Judgment. Jurnal Neo-Bis, 9(2), 66-86. https://doi.org/https://doi.org/10.21107/nbs. v9i2.1274

Libby, R., \& Frederick, D. M. (1990). Experience and the Ability to Explain Audit Findings. Journal of Accounting Research, 28(2), 348-367. https://doi.org/10.2307/2491154

Mohd-Sanusi, Z., Khalid, N. H., \& Mahir, A. (2015). An Evaluation of Clients' Fraud Reasoning Motives in Assessing Fraud Risks: From the Perspective of External and Internal Auditors. International accounting and business conference 2015.

Nahartyo, E. (2012). Desain dan Implementasi Riset Eksperimen. Yogyakarta: UPP STIM YKPN

Novarianto, R. (2010). Pengaruh Pengalaman Auditor Terhadap Keahlian Auditor Mengaudit Perusahaan (Studi Empiris pada Kantor Akuntan Publik di Jakarta). Universitas Islam Negeri Syarif Hidayatullah.

Praditaningrum, A.S., \& Januarti, I. (2012) Analisis faktor-faktor yang berpengaruh terhadap audit judgment (Studi Pada BPK RI Perwakilan Provinsi Jawa Tengah). Simposium Nasional Akuntansi XV.

Putri, P. A., \& Laksito, H. (2013). Pengaruh Lingkungan Etika, Pengalaman Auditor dan Tekanan Ketaatan Terhadap Kualitas Audit Judgment. Diponegoro Journal of Accounting, 2(2), 1-11.

Rahayu, F. P. (2016). Pengaruh Pengetahuan Audit, Pengalaman Audit dan Tekanan
Ketaatan terhadap Audit Judgment (Survey pada Kantor Akuntan Publik di Kota Bandung). Universitas Pasundan.

Ríos-Figueroa, C. B., \& Cardona, R. J. (2013). Does Experience Affect Auditors' Professional Judgment? Evidence From Puerto Rico. Accounting \& Taxation, 5(2), 13-32.

Sanger, C. L., Ilat, V., \& Pontoh, W. (2016). Pengaruh Pengalaman Audit, Keahlian Audit dan Tekanan Ketaatan Terhadap Audit Judgment BPK RI Perwakilan Provinsi Sulawesi Utara. Jurnal Accountability, 5(2), 11-22.

Sim, M. (2010). National Culture Effects on Groups Evaluating Internal Control. Managerial Auditing Journal, 25(1), 5378.

Sumartono, Urusamah, D., \& Hamdani, R. (2020). Skills of the Forensic Accountants in Public Sector Reveal Fraud in Indonesia: An Empirical Investigation. Journal of Accounting and Investment, 21(1), 180-194.

Sunaryo, K., Astuti, S., \& Zuhrohtun. (2019). The role of risk management and good governance to detect fraud financial reporting. Journal of Contemporary Accounting, 1(1), 38-46. https://doi.org/10.20885/jca.vol1.iss1.art4

Suraida, I. (2005). Pengaruh Etika, Kompetensi, Pengalaman Audit dan Risiko Audit terhadap Skeptisisme Profesional Auditor dan Ketepatan Pemberian Opini Akuntan Publik. Sosiohumaniora, 7(3), 186-202. https://doi.org/10.1038/s41562017-0193-3

Watson, D. M. (2003). Cultural Dynamics of Corporate Fraud. Cross Cultural Management: An International Journal, 10(1), 40-54. 